\title{
$11 \mathrm{~h} 30$ - 13h30 | 01/09/2016 Thursday | Room 12
}

\section{GAMES AND THE GRAPHIC REVOLUTION ON TV}

Moderador: JOSÉ DIAS

Diretor de Multimídia - TV Globo/ SET

Virtual Studio \& Production of Augmented Reality

Speakers: David Jorba

Presidente / Vizrt Américas

VR Technologies for Broadcast and Entertainment Speakers: Marcio Aguiar

Enterprise Range Manager at NVIDIA for the Americas / nVidia

A brief view of the future in real time

Speakers: Paulo Souza

Evangelista / Epic Games

Games \& VR: Scenarios

Speakers: Jay Santos

Evangelista / Unity Technologies

Speakers: Eduardo Mancz

VP Broadcast Operations / Vizrt Américas

Speakers: Nilton Guedes

Gerente da linha Enterprise da NVIDIA 


\section{1 h30 - 13h30 | 01/09/2016 Thursday | Room 12}

\section{Content Production}

\section{GAMES AND THE GRAPHIC REVOLUTION ON TV}

Moderador: JOSÉ DIAS

Diretor de Multimídia - TV Globo/ SET

The session will discuss how the use of Virtual Reality and Games will transform the future of Broadcast and New Media by raising the entertainment experience. Different solutions, technologies and trends will be presented in this Panel.

- Virtual Studio \& Production of Augmented Reality Speakers: David Jorba President / Vizrt Américas

Vizrt is world leader in Virtual Studio and Augmented Reality technology. Given recent progress and innovations in the production of virtual graphics and tracking techniques, the use of virtual studios and AR has reached another level. Lower costs, easy maintenance, realistic photographic production, hardware with enhanced performance and simpler work flows have made virtual studios the preference, both for TV networks and for Regional TV Stations for improving news and sports programs.

- VR Technologies for Broadcast and Entertainment Speakers: Marcio Aguiar Enterprise Range Manager at NVIDIA for the Americas / nVidia

- A brief view of the future in real time Speakers: Paulo Souza Evangelista / Epic Games

Why game engines will be the driving force of TV, Movies and Architecture before this decade is out, and a brief look at the trends in computer graphics for games and virtual reality.

- Games \& VR: Scenarios

Speakers: Jay Santos

Evangelista / Unity Technologies

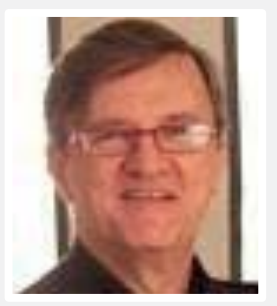

JOSE DIAS

Multimedia Director - TV Globo/ SET

He has dedicated himself over the last 40 years to Television Engineering and Production Techniques and to the study into the use of computers to give a more dynamic visual aspect and the sophisticated techniques for generating images and special effects for TV and the cinema. Between 1979 and 1984 he was leader in the development of the Computer Graphics Technology that revolutionized the visual aspects of the Globo Television Network in the 1980s. Between 1984 and 1994, he was the General Manager 
of Globograph, the company that implemented the use of the CG culture in advertising. Executive Producer of hundreds of commercials, in 1991 he won the Cabore Award as the best supplier of the Brazilian advertising market.In the period from 1991 to 1993 he was General manager at Silicon Graphics in Brazil, responsible for setting up and revealing this renowned company. He has been responsible for countless developments, such as: DIG, equipment for displaying television programming and commercials, in operation and functioning from 1980 until today. He was in charge of the design and development of the first periscope simulator for the Brazilian Navy and which functions nowadays in Rio de Janeiro at the submarine naval base on the Island of Mocangue.Since 1995 he has been developing Virtual Reality techniques applied to Virtual Scenarios, Virtual Advertising, Virtual Actors, Virtual Games, "Tira-Teima" (Video Referee), "VirtuaTeima" (Virtual Referee) and "3DReplay". He has given dozens of talks in Brazil and overseas about his projects and the trends in Virtual reality, Digital Convergence and 3-D Stereoscopy.He is currently Multimedia Director at TV Globo, in charge of leading-edge research and development projects in robotics, VFX, imagen processing, backlot, computer graphics and 3-D stereoscopy. He is a member of the SMPTE, IEEE, The Planetary Society and SET.
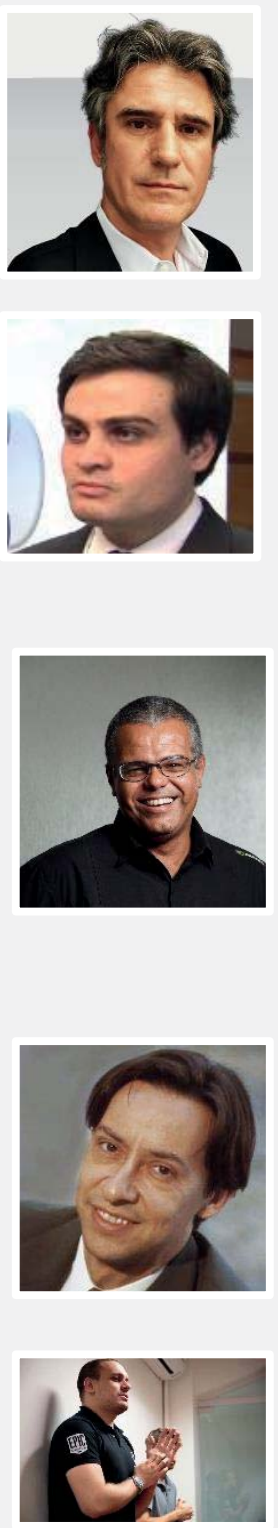

\section{David Jorba}

Presidente - Vizrt Américas

Based at the US headquarters of Vizrt, in New York City, David Jorba joined Vizrt in June 2001 as Director for Creation. Before becoming President of Vizrt Americas, David Jorba was Senior VP for Operations in the Americas, as well as Vizrt General Manager for Southwest Europe. David is a Bachelor of Science, Journalism and Mass Communication from the University of Kansas, and a postgraduate in Design and Visual Communication.

\section{EDUARDO MANCZ}

VP Broadcast Operations / Vizrt Américas

\section{MARCIO AGUIAR}

Enterprise line manager at NVIDIA in Latin America - NVIDIA

Since 2010, Marcio Aguiar has been the Enterprise line manager at NVIDIA in Latin America, responsible for business development with key OEMs and leading professional software companies, while also working as a technology consultant for corporate endusers. Before joining NVIDIA, since 2002 he has worked in the professional audio and video market, providing intelligent display and virtual reality solutions for major companies in Brazil. He obtained a Business degree from Loyola Marymount University, California, in 1995.

\section{NILTON GUEDES}

Gerente da linha Enterprise da NVIDIA

\section{PAULO SOUZA}

\section{Evangelista - Epic Games}

As Unreal Engine Evangelist at Epic Games, Paulo helps Brazilian developers create awesome experiences with the Unreal Engine 4. With 15 years of experience in the games industry as developer and entrepreneur, Paulo helped to fund, design and develop 10 games for global release, ranging from PCs, consoles and the latest mobile platforms. 
SET EXPO PROCEEDINGS - SETEP v. 2, Article 49, 2p

๑ 2016 SET - Brazilian Society of Television Engineering / ISSN (Print): 2447-0481/ ISSN (Online): 2447-049X

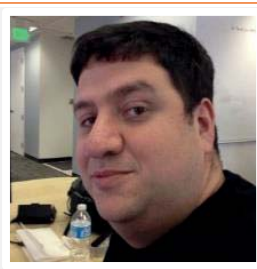

\section{JAY SANTOS}

Field Engineer at Unity Technologies. Evangelist. 